\title{
MONUMENTE EN GEDENKTEKENS OP WEERMAGSTERREINE
}

\author{
Kmdt D. de Klerk en Kapt M. Leach*
}

\section{SA Lugmaggedenkteken}

Die SA Lugmaggedenkteken te Baysheuwel het 'n asemrowende uitsig oor Lugmagbasis Swartkop waar die SA Lugmag in 1920 sy ontstaan gehad het.

'n Kompetisie is deur die Instituut van SA Argitekte in 1958 in samewerking met SA Lugmagfonds en SA Lugmagvereniging geloods. Die beoordeling was onder leiding van Professor John Fassler, Dekaan van die Fakulteit van Argitektuur van die Witwatersrand Universiteit, Johannesburg. Die wenner nl. "Taylor and Taylor" is uit 40 inskrywings gekies.

Die Gedenkteken is ontwerp om die gees van die Lugmag te vertolk. Vanaf die grondvlak skep dit die idee van vliegtuigvlerke. Van bo-af skep dit die indruk van 'n drielem-lugskroef. Die spits simboliseer die hoë ideale wat deur die lugmaglede nagestreef word.
Hierdie Gedenkteken is geopen deur Staatspresident, Sy Edele Adv C.R. Swart op die 1ste September 1963. Konstruksie het in Oktober 1962 begin en die Gedenkteken is voltooi aan die einde van Augustus 1963. Die totale koste was R73 000,00. Die fondse vir die Gedenkteken is gesamentlik deur die SALM en die SALM Vereniging geïn.

Die Gedenkteken is so ontwerp dat dit ' $n$ simboliese vlug voorstel. Om die simboliek te verkry, is drie gepunte vleuels beplan. Die basiese element deurgaans is driehoeke ('n vliegtuigvlerk hoekaansig). Die driehoekvorm is nie net aangewend om die gebou self te ontwerp nie, maar ook om sy verskillende komponente meer prominent te maak. Omdat die aanloopbaan naby die Gedenkteken is, was ' $n$ hoogtebeperking van \pm 16 meter nodig.

Die argitekte was van mening dat wanneer besoekers die Gedenkteken besoek, hulle aandag

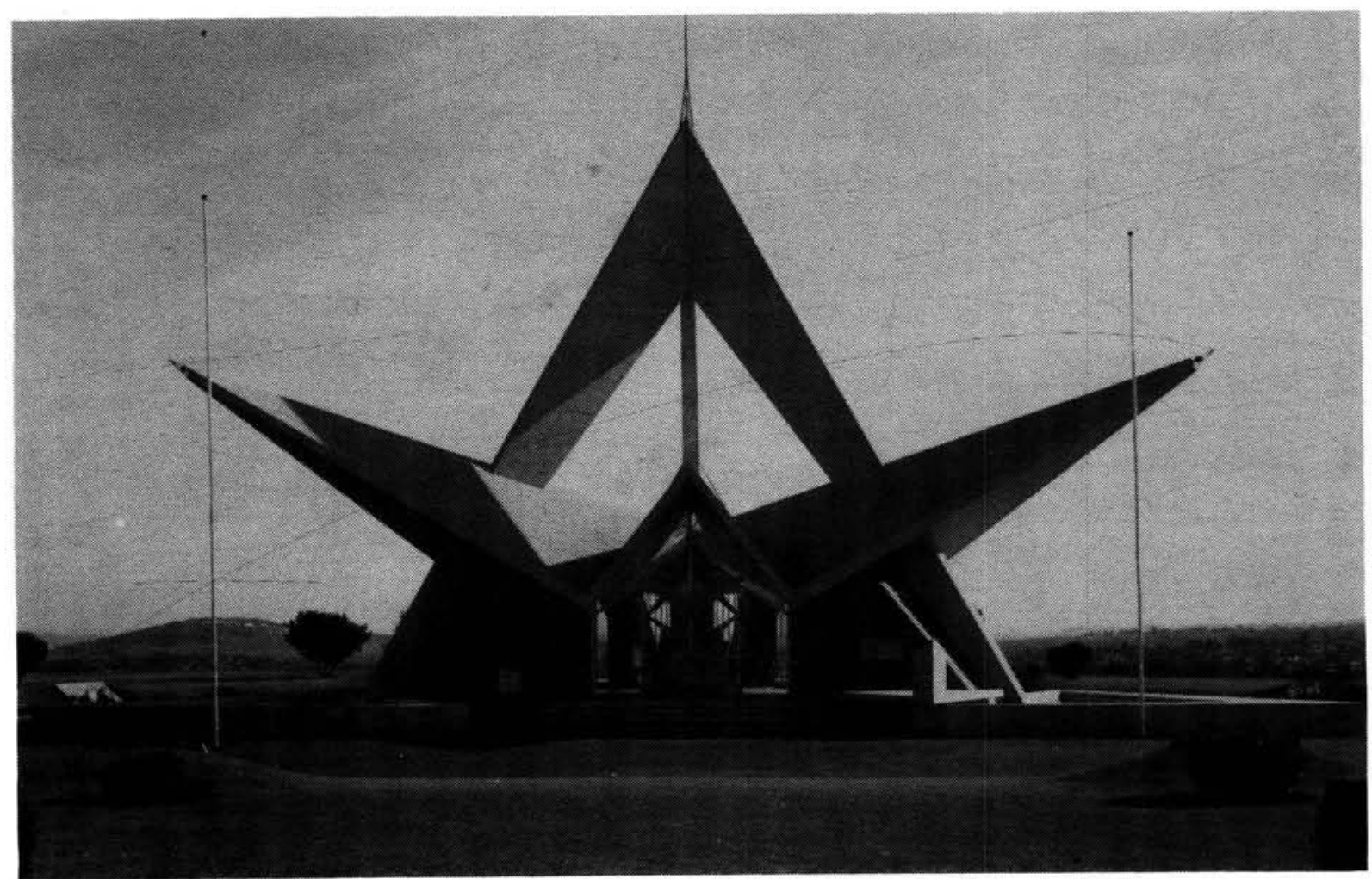

Vooraansig van Gedenkteken. Dle simboliese vlug kan hier bale duidellk gesien word 


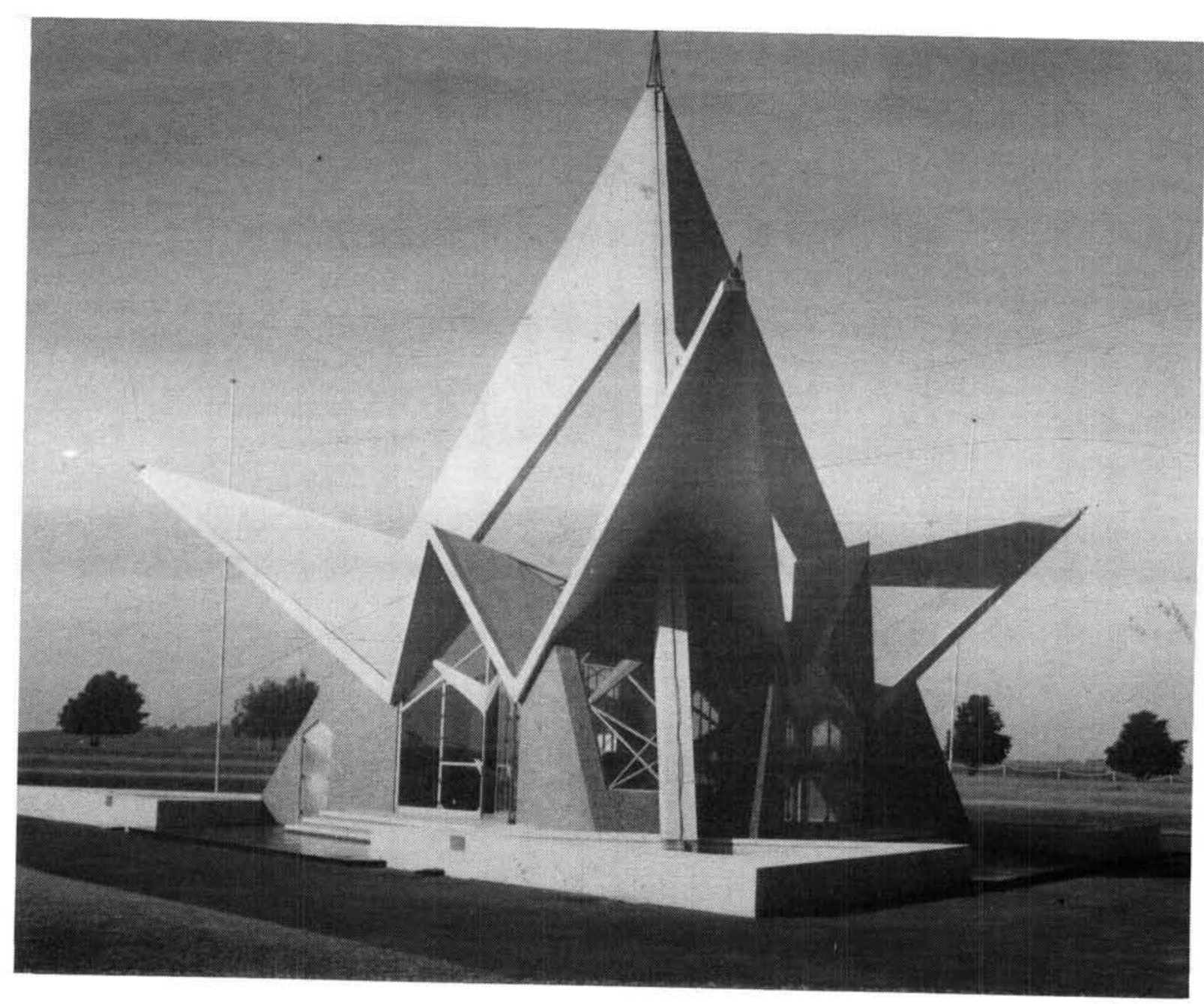

Gedenkteken van sykant. Die deurgaanse gebruik van die driehoek-effek kan duidelik bemerk word

hemelwaarts getrek moet word, daarom is maksimaal van glas in die dakstruktuur gebruik gemaak. Ook wanneer binne die Gedenkteken gestaan word, moet die buitewaartse sig 'n gewyde atmosfeer skep. So ook die gebruik van getinte glas in die kapel - 'n rustige en gewyde atmosfeer heers daar.

Die konstruksie is van gewapende beton gemaak. Die mure en dammetjies het lugmagblou mosaïekteëls in, met 'n simboliese rooi vlek by. Aluminium (vereenselwig met die vliegtuigkonstruksie) is gebruik vir al die metaalkomponente.
Al die vensters vorm ' $n$ ineenskakeling van vlerkvorms. Die trappies is van donkerblou leiklip. Die binne vloer van die Gedenkteken is ineenlopende stervorms in blou en rooi mosaïek. Die Gedenkteken is van Namakwaland oniksmarmer. Die meubels in die kapel is van stinkhout en het ook die driekhoekvorm.

Omdat die gebou simmetries is, moes fyn gelet word op die beligting. Die plafon van die Gedenkteken word belig vanaf ligte wat bo in die gedenksteen, buite sig is. Hierdie lig weerkaats weer teen die Ererol-inskripsies teen die Ge- 


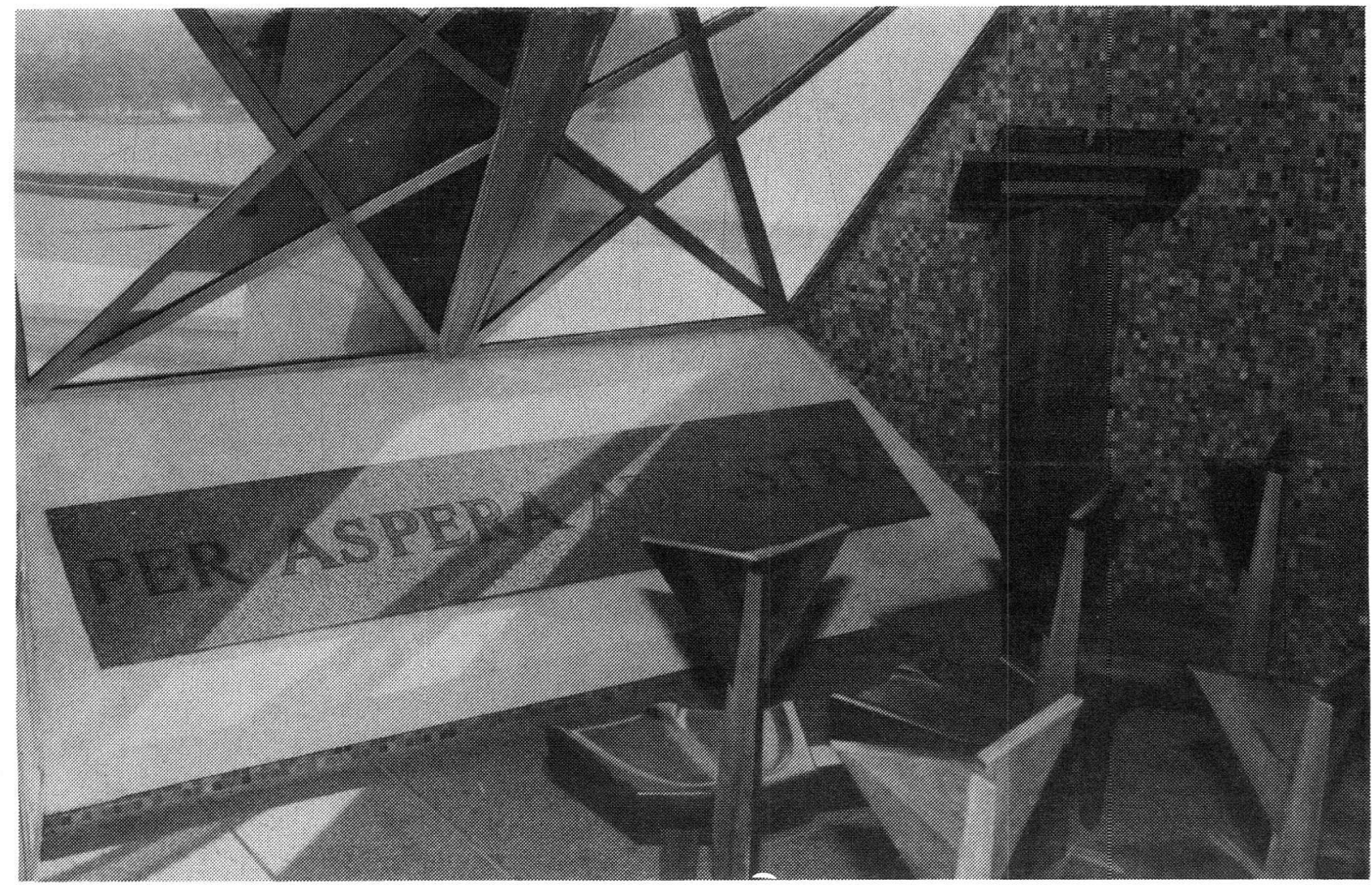

Binne-in die Kapel

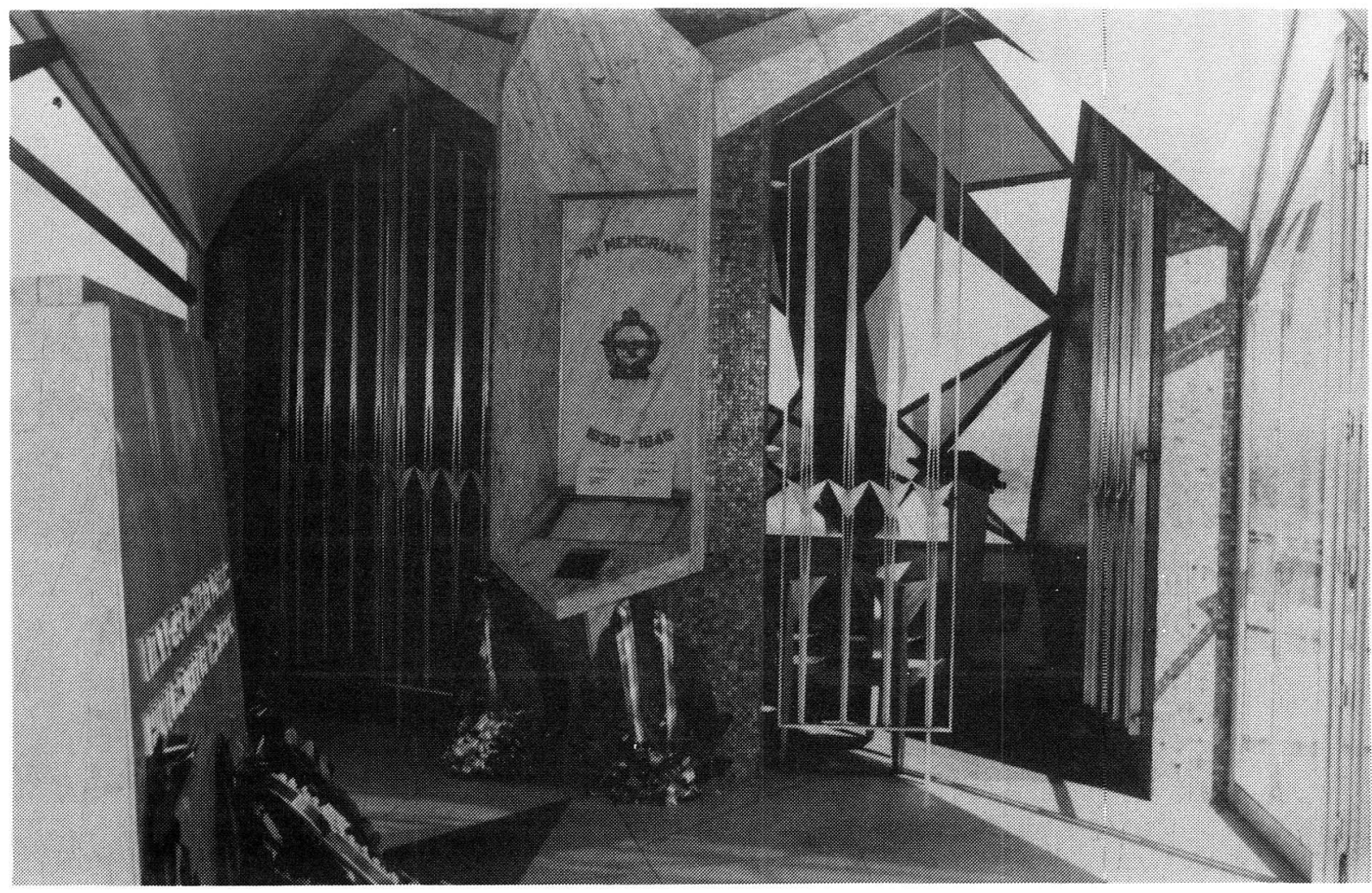

Ingang tot die Kapel. Krans gelê op 6 Mei 1984 tydens die jaarlikse gedenkdiens 
denkteken se sy-mure binne. Buite het die fonteine onderwater beligting. Spreiligte wat in die terrasse rondom die Gedenkteken is, verlig die struktuur van buite. Omdat die Gedenkteken naby die aanloopbaan is, is hindernisligte op die punte van die vleuels aangebring.

Die hekke is afkomstig van 'n eertydse gedenkteken wat by LMB Waterkloof was.

Die Gedenksteen binne-in die Gedenkteken is driehoekig met die SALM Leuse op die een kant. Die tweede kant het die Afrikaanse Skrifgedeelte uit 2 Samuel 1:23. Die derde kant het die Engelse Skrifgedeelte uit Jesaja 40:31.

'n Rostrum buite word gebruik wanneer daar jaarliks ' $n$ gedenkdiens gehou word. Die terrasse voor die Gedenkteken kan vir hierdie geleentheid tot 5000 mense huisves.
Binne die kapel is twee Bybels - 'n Afrikaanse en Engelse - sodat dienste in albei landstale gehou kan word. Naasbestaandes kan hier ook 'n paar oomblikke van stilte hê terwyl hulle aan hulle geliefdes dink wat hulle lewens vir ons voortbestaan opgeoffer het. Ererolle wat die name bevat van alle SALM-lede wat in die Tweede Wêreldoorlog, Korea en in die huidige grensoperasies, asook in vredestyd in die uitvoering van hulle pligte, sedert 1920, gesterf het, word ook binne-in die Gedenkteken bewaar.

Voorwaar het die Gedenkteken in sy doel as struktuur geslaag - 'n tasbare simbool van die verwesenliking van die SALM-ideale.

*Navorsing: Kmdt D. de Klerk (Pers/Fin Koörd) LMB Swartkop met dank aan "South African Architectural Record" vir meeste van die informasie.

Teks: Kapt M. Leach (BPO) LMB Swartkop. Foto's: Sers N.J. Hand - SFI.

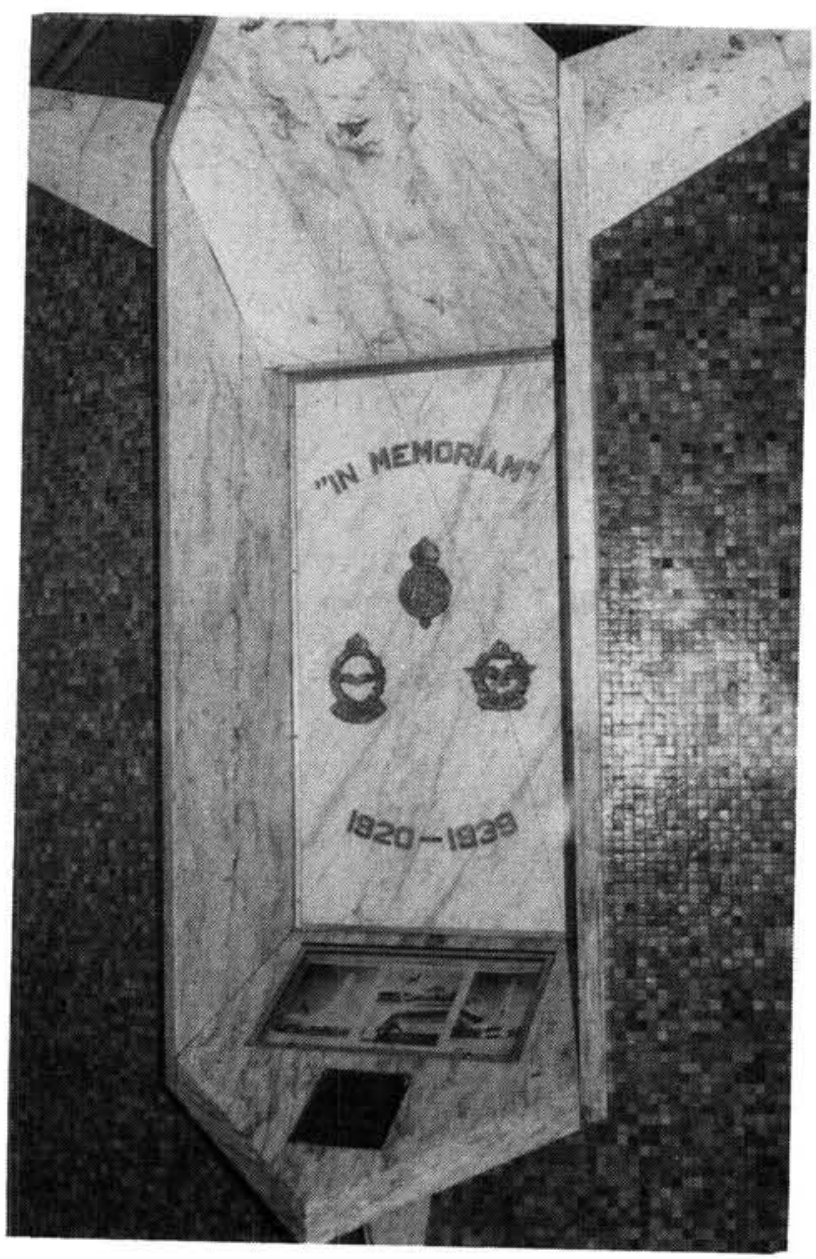



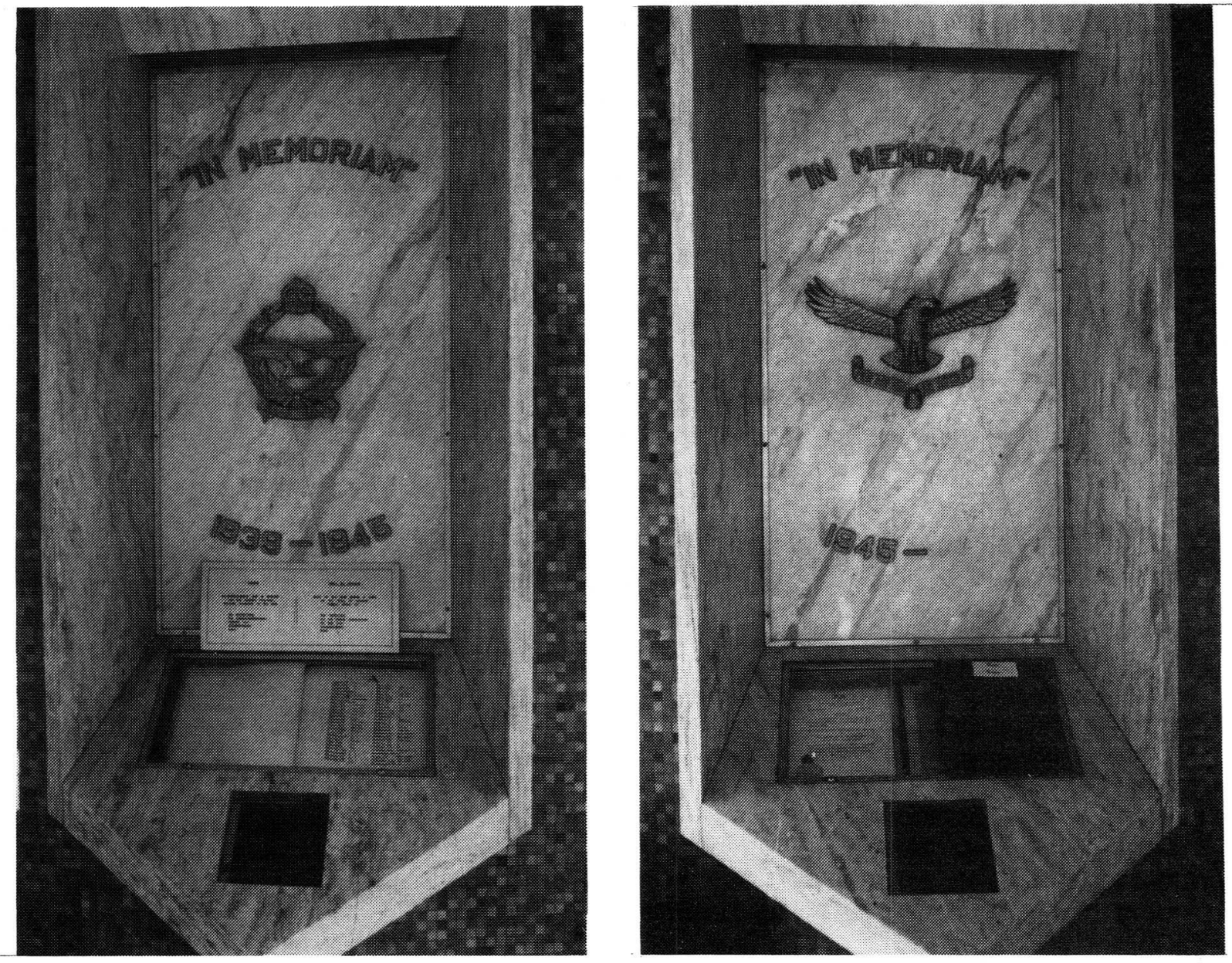

Verskillende "In Memoriam" tydperke wat in die Kapel verewig is 